\title{
The Static Air-Mattress-Inflation Pressure and Nosocomial Pressure Injury-An Innovation in Preventing Pressure Injuries
}

\author{
Aria $\mathrm{ON}^{1}$, and Gbeneol $\mathrm{JT}^{2, *}$ \\ ${ }^{1}$ Consultant Plastic Surgeon, Plastic Division, National Orthopaedic Hospital, Enugu, Nigeria \\ ${ }^{2}$ Burns and Plastic Unit, Department of Surgery, Faculty of Clinical Sciences, College of Health Sciences, University of Port Harcourt, Nigeria
}

*Corresponding author: Gbeneol J Tombari, Burns and Plastic Unit, Department of Surgery, Faculty of Clinical Sciences, College of Health Sciences, University of Port Harcourt, Nigeria, Tel: +2348033426025; E-mail: tombari.gbeneol@uniport.edu.ng

Received: 30 Mar, 2021 | Accepted: 18 May, 2021 | Published: 24 May, 2021

Citation: Aria ON, Gbeneol JT (2021) The Static Air-Mattress-Inflation Pressure and Nosocomial Pressure Injury-An Innovation in Preventing Pressure Injuries. Clin Res Open Access 7(2): dx.doi.org/10.16966/2469-6714.167

Copyright: (C) 2021 Aria ON, et al. This is an open-access article distributed under the terms of the Creative Commons Attribution License, which permits unrestricted use, distribution, and reproduction in any medium, provided the original author and source are credited.

\begin{abstract}
Background: Pressure injuries are said to be nosocomial when they occur after twenty-four (24) hours on admission. Prevention of pressure injuries in high-risk patients such as those with spinal cord injury, the unconscious, and those with femoral neck fracture is essential. The static air-mattress is one of the pressure relieving devices used to prevent pressure injury in low resource countries. However, some patients develop pressure injuries despite being nursed on the air-mattress. The inflation pressure of the static air-mattress is usually not measured, thus is unknown. Therefore, the air-mattress may be over-inflated or under-inflated and ineffective in the prevention of pressure injury.
\end{abstract}

Objective: To determine the role of the inflation pressure of the air-mattress in the development of nosocomial pressure injury amongst a high-risk patient.

Method: This is a prospective study of thirty-five (35) spinal cord injured patients. The static air-mattresses were inflated to and maintained at the recommended pressures of $0.3,0.4$ and $0.5 \mathrm{psi}(16,21$ and $26 \mathrm{mmHg})$. The incidence of nosocomial pressure injuries was analyzed. Data was presented in texts, tables and charts and analysis of the variables done to determine the significance.

Results: There was a male predominance with a mean age of 39 years. The overall incidence of nosocomial pressure injuries amongst patients nursed on air-mattresses inflated to $0.3,0.4$ and $0.5 \mathrm{psi}(16,21$ and $26 \mathrm{mmHg})$, was $5.7 \%$.

Conclusion: Patients at risk of pressure injury who were nursed on air-mattresses inflated to the recommended pressure range of 0.3-0.5 psi (16$26 \mathrm{mmHg}$ ) had a low incidence of nosocomial pressure injury. The static air-mattress should be inflated to and maintained at this recommended pressure range to prevent pressure injuries.

Keywords: Pressure ulcer; Nosocomial pressure injury; Air-mattress pressure; Inflation pressure

\section{Introduction}

Pressure injury is defined as a localized injury to the skin and/or soft tissue as a result of pressure alone, or in combination with shear forces, friction or moisture [1]. It has been referred to as pressure ulcer, decubitus ulcer, bed sore, and recently as pressure injury [2]. It commonly affects immobile patients such as spinal cord injured patients; the elderly with femoral neck fracture and the unconscious; as well as those with vascular diseases [3] Pressure injury is a significant cause of morbidity, with a prevalence of $18.1 \%$ in Europe [4]. Pressure injury has a high-cost burden, with a range of about $\$ 2,000(\mathrm{~N} 720,000)$ to $\$ 20,000(\mathrm{~N} 7,200,000)$ required to treat an ulcer in the United States [5].

Nosocomial pressure injury, also referred to as hospital-acquired pressure injury, is defined as that occurring after the first twenty-four hours of hospital admission [6]. The hospital-acquired pressure injury prevalence rate is expected to be low, however, some hospitals have recorded rates as high as $50 \%[7,8]$. Prevention is the gold standard in pressure injury management [9]. It requires a multidisciplinary approach involving the plastic and orthopedic surgeons, nurses, dieticians, and orthotics unit.

Preventive strategies include, two-hourly turning, skin care and the use of support surfaces [9]. The National Pressure Ulcer Advisory Panel (NPUAP) defines a support surface as "a specialized device for pressure redistribution designed for management of tissue loads, micro-climate and/or other therapeutic functions" [10]. Patients nursed on the air-mattresses are not expected to develop pressure injuries, but this is not always the case. When static air-mattresses are inflated to unmeasured and unknown pressure values, the effectiveness of the pressure mattress cannot be objectively ascertained.

\section{Literature review}

The etiology of pressure injury is multi-factorial and includes extrinsic factors such as pressure, shear forces, friction and moisture; as well as intrinsic factors such as impaired mobility and sensory loss [11]. Pressure has been described as the principal cause of pressure 
injury $[12,13]$. The skin and soft tissue overlying bony prominences of the body, are prone to pressure injury when they are subjected to external pressures exceeding the capillary closing pressure of 32 $\mathrm{mmHg}$ (approximately $0.6 \mathrm{psi}$ ) [13,14]. An audit carried out in United Kingdom, showed the prevalence of nosocomial pressure injury to be as high as 59\% [7]. Another study carried out at the National Orthopedic Hospital, Enugu, reported the incidence of hospitalacquired pressure injury to be as high as $51.6 \%$ [8].

\section{Assessment of air-mattress pressure}

Interface pressure measurement: Several studies have been carried out to determine the pressure measured at the interface between the pressure prone anatomic areas and the air-mattress with the aid of pressure sensors [15-17].

Hand check method: A widely used method which is relatively easy to perform and requires palpating the air-mattress. However, the NPUAP recently released a statement discouraging the routine use of the Hand Check method, stating that it is subjective and may expose patients to shear forces. They recommended using the manufacturer's instruction instead [18].

Manufacturer's instructions: Some manufacturers of airmattresses, do not state their recommended pressure range, instead they instruct that air-mattresses be inflated to levels of comfort or 'firmness' $[19,20]$. This is vague and prone to errors of over or under inflation. Although some manufacturers have clearly recommended an inflation pressure range of 0.3 psi to $0.5 \mathrm{psi}(15.5 \mathrm{mmHg}$ to $26 \mathrm{mmHg}$ ) $[21,22]$. However, a high level of adherence to this recommendation is doubtful.

A study done in Japan, described four (4) inflation pressure values based on a manufacturer's instruction which grouped them into: Very soft, Soft, Medium and Hard. They stated the pressure as $18.8 \pm 1.4$ $\mathrm{mmHg}$ for the very soft mode; and $26.3 \pm 1.9 \mathrm{mmHg}$ for the hard mode [23].

\section{Importance of static air-mattress inflation pressure}

Several studies have been done to assess the interface pressure; however there is a paucity of data on studies done to assess the inner pressure of static air-mattresses. In the developed countries, there is a shift from the static air-mattresses to newer more expensive modifications such as the low air loss, and the alternating pressure air-mattress. However, these sophisticated air-mattresses are not routinely used in resource poor settings, likely due to their higher cost. These more sophisticated air-mattresses have an in- built pressure sensor and controller, which measure and regulate the inner cell pressure [24]. This is lacking in the conventional static air-mattress, which is usually inflated to unmeasured and thus, unknown pressure levels.

In settings such as the study centre, where the inflation pressure is not measured, air-mattress can easily be over-inflated beyond the maximum recommended inflation pressure. An overinflated mattress feels very hard and may exert undue pressure on the overlying pressure prone areas [25]. On the other hand, an under- inflated mattress feels very soft, causing patient to be immersed in the mattress and exposing them to the pressures from the underlying bed frame [26]. Thus, the routine inflation and measurement of the static air-mattress inner pressure is necessary for its effective use. This, in addition to the National Pressure Ulcer Advisory Panel's recommendation to adhere to the manufacturer's instruction, may significantly reduce the hospital-acquired pressure injury prevalence [27].

\section{Aim}

To determine if the air-mattress inflation pressure has a role to play on the development of nosocomial pressure injury in spinal cord injured patients.

\section{Materials and Methods}

This is a prospective interventional study carried out from November 2017 to December 2018 at the National Orthopedic Hospital, Enugu. It involved the measurement of the inflation pressure of the static air-mattress and incidence of nosocomial pressure injury amongst spinal cord injured patients nursed on air-mattresses inflated within the recommended pressure range of 0.3-0.5 psi.

\section{The study population}

The study population comprised of all consecutive adult spinal cord injured patients who presented to the Accident and Emergency Department.

\section{Inclusion criteria}

i. Spinal cord injured patients who presented to the Accident and Emergency Department without signs of pressure injury;

ii. Spinal cord injured patients with a Braden score of 18 or less; iii. Those who gave consent to participate in the study.

\section{Exclusion criteria}

i. Spinal cord injured patients who did not give consent to participate in the study.

ii. Those who already had signs of pressure injuries were excluded from the study.

\section{Sample size}

The sample size was calculated using the formula below [28];

$$
n=Z^{2} \times P Q / d^{2}
$$

$\mathrm{n}=$ the desired total sample size.

$\mathrm{Z}=$ the assumed standard deviation is set at 1.96 which corresponds to $95 \%$ confidence level.

$\mathrm{P}=$ the annual prevalence of spinal cord injured patients from a pilot study done in the National Orthopedic Hospital, Enugu in 2016

=number of spinal cord injured patients/total no of patients admitted;

Number of spinal cord injured patients admitted=38;

Total number of patients admitted $=1726$;

$\mathrm{P}=38 / 1726=0.022$

Annual prevalence of spinal cord injured patients admitted in National Orthopedic Hospital Enugu in 2016 is 2.2\%

$\mathrm{Q}=1.0-\mathrm{p}$

$\mathrm{d}=$ The degree of accuracy $=0.05$

$n=1.96^{2} \times \frac{0.022(1-0.022)}{(0.05)^{2}}$

$\mathrm{n}=33$

The sample size is 33 patients.

Sample size $+20 \%$ attrition $=33+6=39$ patients 


\section{Study protocol}

At presentation to the hospital, consent was sought and gotten from patients with spinal cord injury and the questionnaire was administered by the primary researcher and research assistants. A structured questionnaire comprising of the biodata section, mechanism of injury, timing of presentation, baseline laboratory investigation results and preventive protocol chart was administered. This structured questionnaire was vetted and validated by the research committee and a panel of senior colleagues prior to its administration.

Pressure injury preventive measures such as skin care, perineal hygiene, nutritional rehabilitation and two-hourly turning were commenced. A two-hourly turning and inspection chart was kept for each patient to ensure adherence to the protocol. Baseline serum albumin and blood glucose tests were done for all patients included in the study. All participants in the study were nursed on INTEX airmattress, commenced within the first 24 hours of presentation. The mattresses were inflated by the primary researcher to the recommended pressure range of 0.3-0.5 psi.

A factory calibrated Marshall town analogue pressure gauge, which is certified by the American Society of Mechanical Engineers (ASME), was used to measure and set the pressures and is shown below in figure 1 [29]. An adaptor manufactured by the Scientific Equipment Development Institute, Enugu (SEDI-E), was used to fit the pressure gauge to the mattress inlet valve, in an airtight fashion. The pressure prone areas such as the occiput, sacrum, trochanters and heels, were inspected by the primary researcher, daily for seven (7) days. The quantification of the pressure effects was done using the National Pressure Ulcer Advisory Panel staging criteria. Signs of pressure ulcer development such as erythema, blistering, or oedema, which suggest Stage 1 pressure injury were checked for and charted. Serial clinical photographs of pressure prone areas were taken.

The Marshall town digital pressure gauge is factory calibrated and tested. It has been certified by the American Society of Mechanical Engineers (ASME), with an accuracy of: ASME B40. 1-2/1/2\%.

\section{Data analysis}

Data was analyzed with the software IBM SPSS version 21. Univariate analysis was represented with means and standard deviations for continuous variables and as frequencies and proportions for categorical variables.

\section{Ethical Consideration}

Ethical approval was obtained from the Ethics Committee of National Orthopedic Hospital, Enugu, in line with Helsinki Declaration.

\section{Results}

39 participants were recruited for the study, but 4 participants withdrew from the study before the $7^{\text {th }}$ day. A total of 35 participants completed the study.

There was a predominantly male gender distribution with 29 males and 6 females (Figure 2).

The mean age of the patients was $39.83 \pm 14.13$ years (Figure 3 ).

\section{Incidence of pressure injury}

The incidence of pressure injury is low in this study, with an overall incidence of $5.7 \%$ (Figure 4 ).
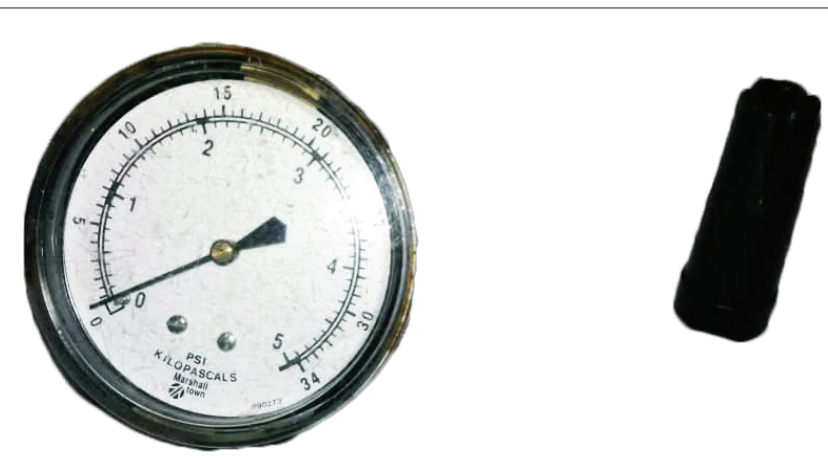

Figure 1: Pressure gauge and adaptor.

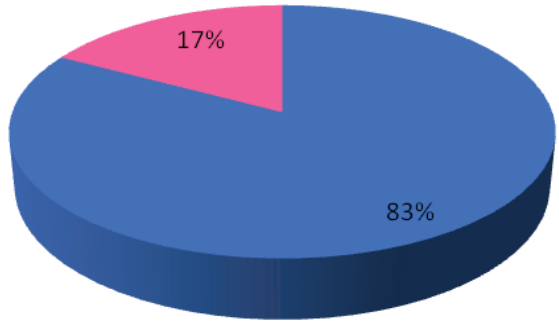

- Male

Eemales

Figure 2: Gender distribution of the study participants.

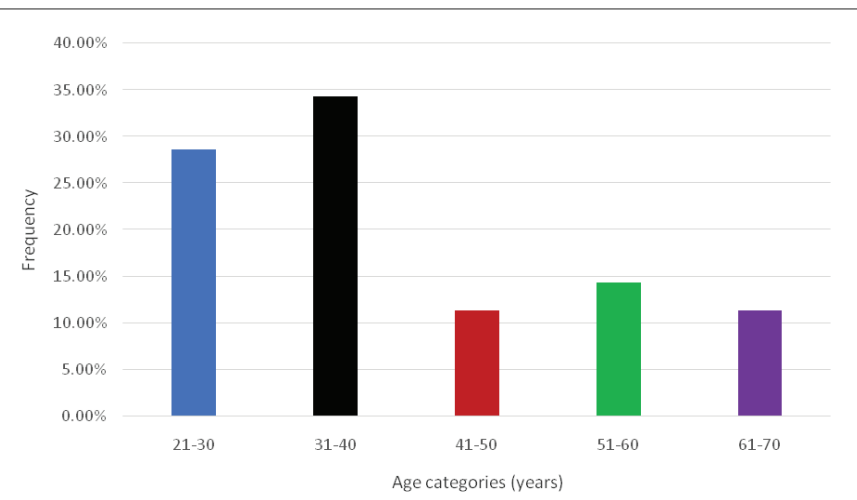

Figure 3: The age categories of the patients.

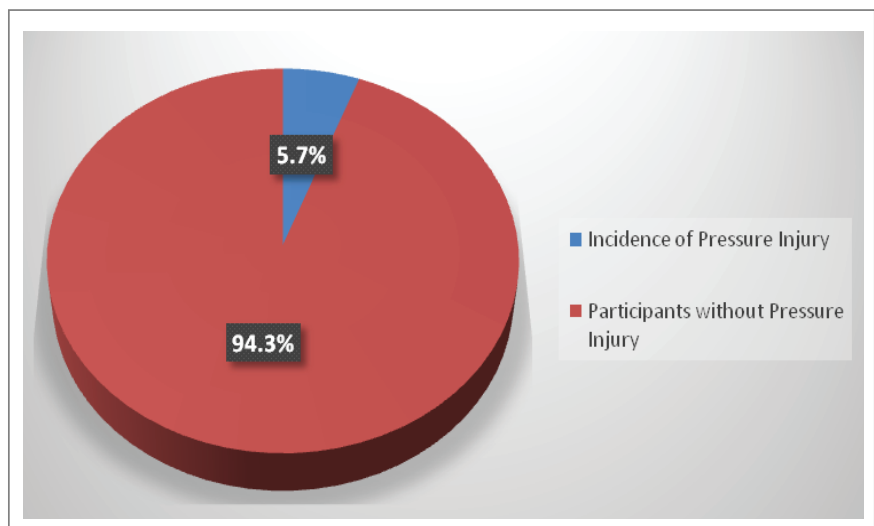

Figure 4: Incidence of hospital acquired pressure injury. 


\section{Other baseline characteristics}

Fourteen participants (40\%) had hypoalbuminemia with values less than $3.4 \mathrm{~g} / \mathrm{dl}$ while 21 participants $(60 \%)$ had serum albumin values at $3.4 \mathrm{~g} / \mathrm{dl}$ or more.

3 participants (8.6\%) had their fasting blood sugar elevated above $125 \mathrm{mg} / \mathrm{dl}$ while thirty-two participants (91.4\%) had their sugar level at $125 \mathrm{mg} / \mathrm{dl}$ or less.

\section{Discussion}

The findings of this study show that the mean age of spinal cord injured patients in this study was $39.83 \pm 14.13$ years, which is similar to the mean age of $38.9 \pm 11.4$ years in a study of spinal cord injured patients done in Abuja, Nigeria [30]. There was a male preponderance of $82.9 \%$, which is in keeping with the gender distribution in previous similar studies done at Abuja and Enugu, with male preponderances of $82.2 \%$ and $81.2 \%$, respectively [ 30,31 ]. The active outdoor lifestyles of young males, make them more prone to road traffic accidents and falls from height, both of which have been identified as causes of spinal cord injury $[30,31]$.

Over the years, emphasis has been placed on the role of higher external pressures as a cause of pressure injury. However, pressure relieving devices when under inflated, have insufficient pressure to keep the patient's body away from the underlying bed frame. This could result in the excessive immersion of the patient into the airmattress and onto the underlying hard bed frame, thus resulting in pressure injuries [32-34]. The overall incidence of hospital-acquired pressure injury in this study is $5.7 \%$, for patients nursed on airmattresses inflated and maintained at 0.3-0.5 psi. Another prospective study carried out in the South-Western part of Nigeria reported a $13.8 \%$ incidence of nosocomial pressure injuries amongst high- risk patients. The $13.8 \%$ incidence could be because the participants were studied for 13 weeks, while this study lasted for 7 days per participant. [35]. In this study, the overall incidence of 5.7\% is much lower than the nosocomial pressure injury incidences of $51.6 \%$ and $49 \%$ reported in two (2) previous studies done at this same study centre $[8,36]$. However, the earlier studies were retrospective, and the researchers may not have been able to exclude other contributory factors such as the presence of pressure injury on admission and the exclusion friction, shear and moisture during patient care.

In a similar research carried out by Gbeneol TJ, et al. [37], the pressure sore recorded in University of Port Harcourt Teaching Hospital was $9 \%$ which is higher than the current study value. This demonstrates that the role of air mattresses gauged at 0.3 to $0.5 \mathrm{psi}$ prevents development of pressure injuries. Gbeneol TJ, et al. studies showed different conditions that increased the risk of development of pressure injuries, cerebrovascular accident, sickle cell disease and Pott disease with pressure injury rate of $19.61 \%, 17.65 \%$ and $27.45 \%$ respectively.

This study monitored each participant for seven (7) days, as studies have shown that most hospital acquired pressure injuries in spinal cord injured patients, occur in the first week and even as early as the first six hours of admission $[38,39]$. Both patients who developed pressure injuries were in their fifties, which is older than the mean age of all participants. A relationship has been described between patient age and pressure injury development; with susceptibility to pressure injury in the adult population, increasing with advancing age [40]. Skin changes such as increased skin fragility and impaired temperature regulation; have been cited as possible reasons for increased proneness to pressure injury with advancing age [40]. In addition, concerning pressure injuries, no study has reported a zero incidence of pressure injury [41]. This study is particularly useful in low resource settings where static air-mattresses are routinely used.

\section{Recommendation}

There should be increased enlightenment on the practicability of measuring the static air-mattress inflation pressure and setting it at $0.3,0.4$, or 0.5 psi $(16,21$ and $26 \mathrm{mmHg})$. A multi-centre study is recommended, as it will involve a large sample size which will be more representative of the study population. This study has contributed to the medical body of knowledge as it shows that the inflation pressure of the static air-mattress can be measured and set to the recommended pressure range of 0.3-0.5 psi.

\section{Conclusion}

This study had a lower overall incidence of pressure injury when compared with previous studies done in similar settings. The inflation pressure of the static air-mattress which is still in use in low-resource settings can be measured and is effective in preventing pressure injuries when it is inflated to and maintained at $0.3-0.5 \mathrm{psi}(16,21$, or $26 \mathrm{mmHg}$ ). Therefore, the inflation pressure of the static air-mattress has a role to play in the development of hospital-acquired pressure injuries in spinal cord injured patients.

\section{Acknowledgements}

We wish to acknowledge Dr I.S. Ogbonnaya and Dr A.O. Udueze for their immense contribution in editing the manuscript.

\section{References}

1. National Pressure Ulcer Advisory Panel, European Pressure Ulcer Advisory Panel, Pan Pacific Pressure Injury Alliance (2014) Prevention and Treatment of pressure ulcers: Quick Reference Guide. Haesler E (eds) $2^{\text {nd }}$ edition, Cambridge Media, Australia 12-19.

2. Wound Care (2016) News National Pressure Ulcer Advisory Panel (NPUAP) Announces a Change in Terminology from Pressure Ulcer to Pressure Injury and Updates the Stages of Pressure Injury. Wound Source.

3. Cullum NA, Petherick E (2008) Pressure Ulcers. BMJ Clin Evid.

4. Vanderwee K, Clark M, Dealey C, Gunningberg L, Defloor T (2007) Pressure Ulcer Prevalence in Europe: a pilot study. J Eval Clin Pract 13: 227-235.

5. Leaf Healthcare (2015) The Financial Impact of Pressure Ulcers. Smith+Nephew, Inc.

6. Jackson SS (2011) Incidence of hospital-acquired pressure ulcers using two different risk assessment scales: results of a retrospective study. Ostomy Wound Manage 57: 20-27.

7. Phillips L, Buttery J (2009) Exploring pressure ulcer prevalence and preventive care. Nurs Times 105: 34-36.

8. Ikechukwu EC, Ayodiipo IO, A Emeka AD, Kayode AJ, Michael NI, et al. (2012) Prevalence and factors associated with healing outcomes of hospital-acquired pressure ulcers among patients with spinal cord injury. J Public Health Epidemiol 4: 44-47.

9. Low L, Vasanwala F, Tay AC (2014) Pressure Ulcer Risk Assessment and Prevention for the Family Physician. Proc Singapore Healthc 23: 142-148.

10. National Pressure Ulcer Advisory Panel (2012) Terms and Definitions Related to Support Surfaces. 
11. Janis JE (2014) Essentials of Plastic Surgery, Second Edition. CRC Press, Taylor \& Francis Group, USA 55: 650-652.

12. Crowe TC, Brockbank CM (2009) Nutrition therapy in the Prevention and Treatment of Pressure Ulcers. Wound Pract Res 17: 90-93.

13. Loerakker S, Baaijens FPT, CWJ Oomens (2007) Aetiology of Pressure Ulcers. Eindhoven: Eindhoven University of Technology Department of Biomedical Engineering Section Materials Technology Division Biomechanics and Tissue Engineering 1-31.

14. Kruger EA, Pires M, Ngann Y, Sterling M, Rubayi S (2013) Comprehensive Management of Pressure Ulcers in Spinal Cord Injury: Current Concepts and Future Trends. J Spinal Cord Med 36: 572-585.

15. Allen V, Ryan DW, Murray A (1994) Measurement of interface pressure between body sites and the surfaces of four specialised air mattresses. Br J Clin Pract 48: 125-129.

16. Rithalia SV, Gonsalkorale M (2000) Quantification of pressure relief using interface pressure and tissue perfusion in alternating pressure air mattresses. Arch Phys Med Rehabil 81: 1364-1369.

17. Tsuchiya S, Sato A, Azuma E, Urushidani H, Osawa M, et al. (2016) The effectiveness of small changes for pressure redistribution; using the air mattress for small changes. J Tissue Viability 25: 135-142.

18. Call E, Deppisch M, Jordan R, Sylvia C, Thurman K, et al. (2015) Hand Check Method: Is it an Effective Method to Monitor for Bottoming Out? A National Pressure Ulcer Advisory Position Statement. National Pressure Ulcer Advisory Panel.

19. Bestway: Owner's Manual (2018) Bestway - Your Fun is Our Business. Bestway.

20. Aerobed. Instruction Manual. Aerobed Double Airbeds with pump in premium quality.

21. Decathlon (2020) Air Seconds Technology: user instructions! Quechua, UK.

22. Decathlon (2020) How Do I Use My Inflatable Mattress? Quechua, UK.

23. Kamikawa N, Taito S, Takahashi M, Sekikawa K, Hamada H (2016) Effect of Different Levels of Pressure Relieving Air- Mattress Firmness on Cough Strength. PloS One 11: e0146714.

24. National Clinical Guideline Centre (UK) (2014) The Prevention and Management of Pressure Ulcers in Primary and Secondary Care. London: National Institute for Health and Care Excellence (UK).

25. NHS 111 Wales (2020) Encyclopedia: Pressure Ulcers. Welsh Ambulance Services NHS Trust, UK.

26. International Review: Pressure ulcer prevention: pressure, shear, friction and microclimate in context. A consensus document. (2010) London: Wounds International.
27. National Pressure Ulcer Advisory Panel (NPUAP) (2001) Pressure ulcers in America: prevalence, incidence, and implications for the future. An executive summary of the National Pressure Ulcer Advisory Panel monograph. Adv Skin Wound Care 14: 208-215.

28. Suresh KP, Chandrashekara S (2012) Sample Size estimation and power analysis for clinical research studies. J Hum Reprod Sci 5: 7-13.

29. Marsh Bellofram. Product catalog 2012. BelGAS, Marsh Bellofram, USA.

30. Kawu AA (2012) Pattern and presentation of spine trauma in Gwagwalada-Abuja, Nigeria. Niger J Clin Pract 15: 38-41.

31. Nwankwo OE, Uche EO (2013) Epidemiological and treatment profiles of spinal cord injury in Southeast Nigeria. Spinal Cord 51: 448-452.

32. Suresh KP, Chandrashekara S (2012) Sample size estimation and power analysis for clinical research studies. J Hum Reprod Sci 5: 7-13.

33. Cooper R, Ohnabe H, Hobson DA (2006) An Introduction to Rehabilitation Engineering. CRC Press, Taylor \& Francis Group, USA.

34. Alpha Tekniko (2018) Common Healthcare Mattress Terminology: What do all those terms really mean? Mattress Terminology, Alpha Tekniko, USA.

35. Onigbinde AT, Ogunsanya GI, Oniyangi SO (2012) Pressure Ulcer Incidence among High-Risk Patients in Nigeria. $\mathrm{Br} J$ Nurs 21: $\mathrm{S} 4, \mathrm{~S} 6, \mathrm{~S} 8-\mathrm{S} 10$.

36. Nwadinigwe CU, Amaefule K, Uduezue AO (2013) Pattern of Pressure Sores in Spinal Injured Patients within the First Six Months. Niger J Orthoped Trauma 12: 56-61.

37. Gbeneol TJ, Nwachukwu AC (2021) A Retrospective Study of the Prevalence of Pressure Sores: The University of Port Harcourt Teaching Hospital Experience. Niger Health J 21: 34-40

38. Iyun AO, Malomo AO, Oluwatosin OM, Ademola SA, Shokunbi MT (2011) Pattern of Presentation of Pressure Ulcers in Spinal Cord Injured Patients in University College Hospital Ibadan. Int Wound J 9: 206-213.

39. Lyder CH, Ayello EA (2008) Pressure Ulcers: A Patient Safety Issue. In: Hughes RG (eds) Patient Safety and Quality: An Evidence-Based Handbook for Nurses. Rockville (MD): Agency for Healthcare Research and Quality (US).

40. Perneger TV, Héliot C, Raë AC, Borst F, Gaspoz JM (1998) Hospital Acquired Pressure Ulcers Risk Factors and Use of Preventive Devices. Arch Intern Med 158: 1940-1945.

41. Thomas E, Vinodkumar S, Mathew S, Setia MS (2015) A Study of Factors Associated with Risk for Development of Pressure Ulcers: A Longitudinal Analysis. Indian J Dermatol 60: 566-572. 